\title{
UPAYA PENINGKATAN KINERJA LAYANAN SEKRETARIAT DPRD KABUPATEN SOPPENG
}

\section{EFFORTS TO IMPROVE THE PERFORMANCE OF THE SOPPENG DISTRICT SECRETARIAT SERVICE DPRD}

\author{
Anirwan ${ }^{1}$, Aswar Annas ${ }^{2}$ \\ 1Universitas Pancasakti Makassar \\ ${ }^{2}$ Institut Teknologi dan Pariwisata Amanaggapa Makassar \\ Email: anirwan.science@gmail.com
}

\begin{abstract}
The purpose of this study was to determine efforts to improve the performance of the Soppeng Regency DPRD Secretariat services. The research method used is the input method (the infut storage), namely the Internal Factor Evaluation (IFE) Matrix and the External Factor Evaluation (EFE) and matching (the matching stage) Matrix, the SWOT matrix. The IFE matrix and EFE matrix are made using five steps, namely identification of key internal and external factors, the weighting stage, the scale setting stage, the weight and scale calculation stage, the sum of the weighting stages with the rating scale, while the preparation of a strategy for improving service performance is done by selecting the top 5 of the highest scoring value of the internal and external key factors which are then entered into the SWOT matrix for matching (matching tool). The results showed that efforts to improve service performance of the Soppeng District DPRD Secretariat had received good ratings by members of the DPRD although it was still necessary to continue to improve services in order to achieve a very good rating. Therefore, to improve the performance of the DPRD Secretariat services, a strategy that can be carried out is to provide online-based aspiration media in support of the work of DPRD members and to increase socialization and publication related to the duties, functions and performance of DPRD members; increasing education and training support for secretariat staff in creating the professionalism of the DPRD secretariat apparatus and updating information and regulations through the DPRD Website integrated with the central, provincial and district government websites; increasing the adaptability of DPRD secretariat employees in adjusting regulatory changes without reducing service quality; providing TV information on the activities of DPRD members based on IT and making regulation pocket books in support of the performance of DPRD members.
\end{abstract}

Keywords: Strategy; Improved Service Performance; Organization

Journal of Governance and Local Politics (JGLP)

ISSN (online): 2684-9992, Volume: 2, Nomor: 2, November 2020 


\begin{abstract}
ABSTRAK
Tujuan penelitian ini adalah untuk mengetahui upaya peningkatan kinerja layanan Sekretariat DPRD Kabupaten Soppeng. Metode penelitian yang digunakan adalah metode masukan (the infut storage), yakni Matriks Internal Factor Evaluation (IFE) dan Matriks Eksternal Factor Evaluation (EFE) dan pencocokan (the matching stage), yakni matriks SWOT. Matriks IFE dan matrix EFE dibuat dengan menggunakan lima langkah, yakni identifikasi factor kunci internal dan eksternal, tahap pemberian bobot, tahap penetapan skala, tahap kalkulasi bobot dan skala, tahap menjumlahkan bobot dengan skala penilaian, sedangkan penyusunan strategi peningkatan kinerja layanan dilakukan pemilihan 5 besar dari nilai scoring tertinggi dari faktorfaktor kunci internal dan ekternal yang kemudian dimasukkan kedalam matrix SWOT untuk dilakukan pencocokan (matching tool). Hasil penelitian menunjukkan bahwa upaya peningkatan kinerja layanan Sekretariat DPRD Kabupaten Soppeng telah mendapatkan penilaian baik oleh anggota DPRD meskipun masih tetap perlu untuk terus dilakukan peningkatan layanan agar bisa mencapai penilaian sangat baik. Oleh karena itu, untuk meningkatkan kinerja layanan Sekretariat DPRD maka strategi yang dapat dilakukan adalah penyediaan media aspirasi berbasis online dalam mendukung kerja- kerja anggota DPRD dan peningkatan sosialisasi dan publikasi terkait tugas, fungsi dan kinerja anggota DPRD; peningkatan dukungan pendidikan dan pelatihan pegawai sekretariat dalam menciptakan profesionalitas aparatur sekretariat DPRD dan update informasi dan regulasi melalui Website DPRD yang terintegrasi dengan website pemerintah pusat, provinsi dan kabupaten; peningkatan kemampuan adaptasi pegawai secretariat DPRD dalam menyesuaikan perubahan regulasi tanpa mengurangi kualitas layanan; penyediaan TV informasi kegiatan anggota DPRD yang berbasis IT dan pembuatan buku saku regulasi dalam mendukung kinerja anggota DPRD.
\end{abstract}

Kata kunci : Strategi; Peningkatan Kinerja Layanan; Organisasi.

\title{
PENDAHULUAN
}

Sekretariat DPRD berdasarkan pasal 204 Undang-Undang nomor 17 tahun 2014 tentang Pemerintah Daerah dan pasa 15 ayat 2 Peraturan Pemerintah Nomor 18 tahun 2016 tentang Organisasi Perangkat Daerah, merupakan salah satu perangkat daerah yang dibentuk untuk mendukung 
kelancaran pelaksanaan tugas dan wewenang DPRD kabupaten/kota. Sekretariat DPRD merupakan unsur pelayanan administrasi dan pemberian dukungan terhadap tugas dan fungsi DPRD kabupaten/kota. Kemudian Undang-Undang tersebut menjadi dasar ditetapkan Peraturan Daerah nomor 5 tahun 2016 tentang Pembentukan dan Susunan perangkat daerah Kabupaten Soppeng. Selanjutnya Peraturan Daerah tersebut dijabarkan dalam Peraturan Bupati Nomor 23 tahun 2019 tentang Kedudukan, Susunan Organisasi, Tugas dan Fungsi serta Tata Kerja Sekretariat DPRD Kabupaten Soppeng.

Pada pasal 204 Undang-Undang nomor 23 tahun 2014 tentang Pemerintah Daerah dan pasal 5 ayat 2 Peraturan Pemerintah Nomor 18 Tahun 2016 tentang Organisasi Perangkat Daerah, Sekretariat DPRD sebagai salah satu perangkat daerah, dibentuk untuk mendukung kelancaran pelaksanaan tugas dan wewenang DPRD kabupaten/kota. Sekretariat DPRD merupakan unsur pelayanan administrasi dan pemberian dukungan terhadap tugas dan fungsi DPRD kabupaten/kota.

Berdasarkan Undang-Undang nomor 17 tahun 2014 tentang Pemerintah Daerah. Kemudian pada Peraturan Pemerintah Nomor 18 Tahun 2016 tentang Organisasi Perangkat Daerah, yang selanjutnya ditetapkan dalam Peraturan Daerah Nomor 5 Tahun 2016 tentang Pembentukan dan Susunan perangkat daerah Kabupaten Soppeng. Peraturan Daerah tersebut selanjutnya dijabarkan dalam Peraturan Bupati Nomor 32 Tahun 2019 tentang Kedudukan, Susunan Organisasi, Tugasdan Fungsi serta Tata Kerja Sekretariat DPRD Kabupaten Soppeng.

Sekretariat DPRD Kabupaten Soppeng mempunyai tugas menyelenggarakan administrasi kesekretariatan dan keuangan, mendukung pelaksanaan tugas dan fungsi DPRD Kabupaten Soppeng, serta menyediakan dan mengoordinasikan tenaga ahli yang diperlukan oleh DPRD Kabupaten Soppeng dalam melaksanakan hak dan fungsinya sesuai dengan kebutuhan. 
Sekretariat DPRD Kabupaten Soppeng dalam menyelenggarakan tugasnya, mempunyai fungsi sebagai berikut: 1) penyelenggaraan administrasi kesekretariatan Dewan Perwakilan Rakyat Daerah; 2) penyelenggaraan administrasi keuangan Dewan Perwakilan Rakyat Daerah; 3) fasilitasi penyelenggaraan rapat-rapat Dewan Perwakilan Rakyat Daerah; 4) Penyediaan dan pengkordinasian tenaga ahli yang diperlukan oleh Dewan Perwakilan Rakyat Daerah; 5) pembinaan, pengkordinasian, pengendalian dan pengawasan tugas kepala bagian; dan 6) pelaksanaan fungsi lain sesuai dengan kewenangan dan bidang tugasnya.

Sekretariat DPRD Kabupaten Soppeng dipimpin oleh sekretaris DPRD yang dalam melaksanakan tugasnya secara teknis operasional berada di bawah dan bertanggung jawab kepada pimpinan DPRD Kabupaten Soppeng dan secara administratif bertanggung jawab kepada Bupati Soppeng melalui Sekretaris Daerah Kabupaten Soppeng. Dalam menjalankan tugas Sekretaris DPRD Kabupaten Soppeng dibantu oleh 3 Kepala bagian yaitu; Kepala Bagian Umum dan Keuangan, Kepala Bagian Persidangan dan Perundang-undangan, dan Kepala Bagian Fasilitasi Penganggaran dan Pengawasan.

Setiap Kepala Bagian dibantu masing-masing 2 kepala Sub Bagian. Kepala Bagian Umum dan Keuangan dibantu oleh Sub Bagian Perencanaan, Pelaporan dan Keuangan, dan Sub Bagian Umumdan Kepegawaian yang dipimpin oleh seorang Kepala Sub Bagian. Kepala Bagian Persidangan dan Perundang-Undangan dibantu oleh Sub Bagian Kajian Perundang-undangan, dan Sub Bagian Persidangan, Risalah dan Publikasi dipimpin oleh seorang Kepala Sub Bagian. Kepala Bagian Fasilitasi Penganggaran dan Pengawasan dibantu oleh SubBagian Fasilitasi Penganggaran dan Sub Bagian Fasilitasi Pengawasan dipimpin oleh seorang Kepala Sub Bagian.

Berdasarkan observasi awal bahwa kinerja layanan Sekretariat DPRD Kabupaten Soppeng belum maksimal yang disebabkan karena kurangnya pemahaman anggota terhadap peraturan perundang-undangan, keterbatasan 
kapasitas sumber daya manusia yang professional yang memahmi tugas dan fungsinya, belum tersedianya buku regulasi sebagai salah satu bentuk pelayanan dalam rangka mendukung kelancaran tugas anggota DPRD, belum optimalnya pemanfaatan sarana teknologi informasi dalam membantu kinerja layanan Sekretariat DPRD terhadap kebutuhan informasi anggota DPRD, pelaksanaan system dan prosedur pelayanan yang belum optimal.

Berangkat permasalah tersebut di atas, maka tujuan penelitian ini adalah untuk mengetahui gambaran upaya peningkatan kinerja layanan Sekretariat DPRD Kabupaten Soppeng sehingga dapat menemukan strategi yang tepat untuk meningkatkan kinerja layanan dalam mendukung pelaksanaan tugas dan fungsi anggota DPRD.

Annas dkk (2019) dalam penelitiannya menunjukkan bahwa dalam peningkatan pelayanan kinerja diperlukan optimalisasi fungsi organisasi dan peningkatan ketersediaan fasilitas penunjang pengetahuan dan kinerja anggota sebuah lembaga. Sutanti (2014) dalam temuannya menguraikan strategi peningkatan layanan di sekretariat DPRD dengan cara: menempatkan pegawai sesuai dengan kemampuan atau kompetensi sehingga mampu menjalankan pekerjaan sesuai uraian tugas pokok dan fungsinya, Mengupayakan peningkatan Sumber Daya Manusia yang disesuaikan dengan kebutuhan pegawai agar lebih bermanfaat dan dapat menunjang aktivitasnya, serta memanfaatkan anggaran yang tersedia secara optimal dan merencanakan kebutuhan anggaran untuk masa yang akan datang guna mencukupi kurangnya sarana dan prasarana kantor penunjang kegiatan pelayanan.

Tingginya komitmen pegawai Sekretariat DPRD untuk bekerja secara optimal dalam melayani anggota DPRD merupakan salah satu faktor untuk meningkatkan layanan sekeretariat DPRD (Nim, 2016). Kulitas dan kuantitas pegawai Sekretariat DPRD dan motivasi kerja merupakan hal yang dominan dalam memberikan pelayanan yang berkualitas sebagaimana yang diteliti oleh 
(Septiani, 2018; Zamzam, 2016; Mukhlishoh et al, 2016; Harahap et al, 2016; Novitasari, 2014).

\section{METODE PENELITIAN}

Menurut Rangkuti (2005), analisis strategi dan pilihan strategi mencoba menetapkan macam tindakan alternatif yang mungkin terbaik bagi suatu daerah dalam usaha mewujudkan misi dan sasarann Aplikasi untuk menentukan strategi utama berdasarkan konsep Rangkuti dilakukan melalui pemakaian beberapa matriks dengan dua tahap pelaksanaan, yaitu tahap 1 : tahap masukan (the infut storage), yakni Matriks Internal Factor Evaluation (IFE) dan Matriks Eksternal Factor Evaluation (EFE) kemudian tahap 2 : tahap pencocokan (the matching stage), yakni matriks SWOT.

Penyusunan strategi ini pada dasarnya tidak hanya sekedar kegiatan pengumpulan data, tetapi juga merupakan suatu kegiatan, pengklasifikasian dan pra-analisis. Pada tahap ini data dibedakan menjadi dua, yaitu data eksternal dan internal. Dalam evaluasi faktor strategis yang digunakan adalah model matriks faktor strategis eksternal dan matriks faktor strategis internal. Setelah penetapan kekuatan dan kelemahan antara faktor internal dengan faktor eksternal, maka disusunlah hasil analisis melalui suatu prosedur Internal Factor Evaluation (IFE) dan External Factor Evaluation (EFE). Matrix IFE dan EFE digunakan untuk mengetahui kekuatan dan kelemahan serta peluang dan ancaman dalam mengidentifikasi permasalahan yang timbul dalam kinerja layanan Sekretariat DPRD dikabupaten Soppeng.

Faktor Evaluasi Internal (IFE) matriks adalah alat manajemen strategis untuk audit atau mengevaluasi kekuatan dan kelemahan dan Faktor Evaluasi Eksternal (EFE) matriks adalah alat manajemen strategis untuk audit atau mengevaluasi peluang dan ancaman/hambatan utama terhadap permasalahan dalam peningkatan kinerja layanan Sekretariat DPRD di Kabupaten Soppeng. Matriks IFE juga menyediakan dasar untuk mengidentifikasi dan mengevaluasi 
hubungan di antara fungsional permasalahan tersebut yang selanjutnya digunakan dalam perumusan strategi. Matriks IFE dan matrix EFE dibuat dengan menggunakan lima langkah, yakni identifikasi factor kunci internal dan eksternal, tahap pemberian bobot, tahap penetapan skala, tahap kalkulasi bobot dan skala, tahap menjumlahkan bobot dengan skala penilaian.

Untuk menyusun strategi peningkatan kinerja layanan Sekretariat DPRD Kabupaten Soppeng digunakan alanalis SWOT. Penyusunan strategi peningkatan kinerja layanan Sekretariat DPRD Kabupaten Soppeng dilakukan pemilihan 5 besar dari nilai scoring tertinggi dari faktor-faktor kunci internal dan ekternal yang kemudian dimasukkan kedalam matrix SWOT untuk dilakukan pencocokan (matching tool).

\section{HASIL DAN DISKUSI}

\section{Faktor yang Mempengaruhi Kinerja Layanan Sekretariat DPRD Kabupaten Soppeng}

Pada tahap ini data dibedakan menjadi dua, yaitu data eksternal dan internal Sekretariat DPRD Kabupaten Soppeng. Setelah penetapan kekuatan, kelemahan, peluang dan ancaman/hambatan terhadap faktor internal dan faktor eksternal, maka disusunlah hasil analisis melalui suatu prosedur Internal Factor Evaluation (IFE) dan External Factor Evaluation (EFE) yang kemudian Matrix IFE dan EFE digunakan untuk mengidentifikasi permasalahan yang timbul dalam peningkatan kinerja layanan Sekretariat DPRD Kabupaten Soppeng.

Adapun Internal Factor Evaluation (IFE) dan Eksternal Factor Evaluation (EFE) yang mempengaruhi kinerja layanan Sekretariat DPRD Kabupaten Soppeng adalah sebagai berikut :

1) Internal Factor Evaluation (IFE) pada Sekretariat DPRD Kabupaten Soppeng

Faktor Evaluasi Internal (IFE) matriks adalah alat manajemen strategis untuk audit atau mengevaluasi faktor-faktor kekuatan dan kelemahan utama terhadap permasalahan peningkatan kinerja layanan Sekretariat DPRD Kabupaten Soppeng. Pada Faktor Evaluasi Internal (IFE) terdapatdua matriks yakni matriks kekuatan dan 
matriks kelemahan. Matriks tersebut merupakan hasil pengklasifikasian dan praanalisis kekuatan dan kelemahan terhadap kinerja layanan Sekretariat DPRD Kabupaten Soppeng. Faktor-faktor kunci pada faktor kekuatan dan kelemahan diberikan penilaian skala rating dan nilai bobot yang kemudian dilakukan kalkulasi bobot dan skala untuk mendapatkan nilai scoring di setiap faktor- factor kunci. Sebagaimana yang terlihat pada Tabel 1 dan 2 berikut ini.

Tabel 1.

Matriks IFE (Kekuatan) Sekretariat DPRD Kabupaten Soppeng

\begin{tabular}{|c|c|c|c|c|}
\hline \multirow[b]{2}{*}{ No } & \multirow[b]{2}{*}{ Faktor-Faktor Kekuatan } & \multicolumn{2}{|c|}{ Total } & \multirow{2}{*}{$\begin{array}{l}\text { Skore } \\
\text { Rating x } \\
\text { Bobot }\end{array}$} \\
\hline & & Rating & Bobot & \\
\hline 1 & $\begin{array}{l}\text { Ketersediaan fasilitas rapat-rapat anggota DPRD sudah } \\
\text { representative }\end{array}$ & 3,14 & 0,06 & 0,197 \\
\hline 2 & $\begin{array}{l}\text { Terlaksananya dengan baik tugas sekretariat DPRD atas } \\
\text { pelayanan terhadap hak keuangan anggota DPRD }\end{array}$ & 3,21 & 0,06 & 0,207 \\
\hline 3 & $\begin{array}{l}\text { Tersedianya dukungan anggaran yang cukup memadai dalam } \\
\text { menfasilitasi kegiatan DPRD melaksanakan Tugas Pokok } \\
\text { dan Fungsinya }\end{array}$ & 3,07 & 0,06 & 0,198 \\
\hline 4 & Tersedianya jumlah aparatur yang memadai & 3,07 & 0,07 & 0,204 \\
\hline 5 & $\begin{array}{l}\text { Kemitraan Sekretariat DPRD dengan media dan kelompok } \\
\text { kepentingan serta pemerintah daerah untuk sosialsasi } \\
\text { program }\end{array}$ & 3,07 & 0,07 & 0,207 \\
\hline 6 & $\begin{array}{l}\text { Sekretariat DPRD mampu menyediakan dukungan } \\
\text { Tenaga Ahli Fraksi, Kelompok Pakar, staf secretariat fraksi } \\
\text { untuk kelancaran tugas dan fungsi DPRD }\end{array}$ & 3,29 & 0,07 & 0,214 \\
\hline 7 & Tersedianya Ruangan dan Sarana Staf Ahli Fraksi & 0,14 & 0,01 & 0,001 \\
\hline 8 & Memahami Tatib DPRD & 0,29 & 0,01 & 0,002 \\
\hline 9 & $\begin{array}{l}\text { Pengeahuan Terakait Regulasi-Regulasi Setiap Pembahasan } \\
\text { RANPERDA }\end{array}$ & 0,29 & 0,01 & 0,002 \\
\hline 10 & $\begin{array}{l}\text { Sekretariat Yang Menyediakan Tugas Ahli Pada Setiap Alat } \\
\text { Kelengkapan DPRD }\end{array}$ & 0,21 & 0,01 & 0,001 \\
\hline 11 & Pengawasan DPRD Terhadap Eksekutif Sudah Maksimal & 0,07 & 0,01 & 0,000 \\
\hline 12 & $\begin{array}{l}\text { Penyusunan Perda Dari Lembaga DPRD Sudah Menyentuh } \\
\text { Kebutuhan Masyarakat }\end{array}$ & 0,21 & 0,00 & 0,001 \\
\hline 13 & $\begin{array}{l}\text { Frekuensi Sekretariat DPRD Berkoordinasi Dengan DPRD } \\
\text { Terkait Rencana Kerja DPRD }\end{array}$ & 0,14 & 0,00 & 0,001 \\
\hline 14 & $\begin{array}{l}\text { Penyususnan Rencana Kerja DPRD Tepat Waktu Sebelum } \\
\text { Penyususnan Rencana Kerja Sekretariat DPRD }\end{array}$ & 0,29 & 0,01 & 0,002 \\
\hline 15 & Ditempatkannya Pegawai Yang Tidak Sesuai Kemampuan & 0,21 & 0,01 & 0,001 \\
\hline
\end{tabular}




\begin{tabular}{|c|l|c|c|c|}
\hline 16 & Suasana Lingkungan Yang Kotor & 0,21 & 0,00 & 0,001 \\
\hline 17 & $\begin{array}{l}\text { Adanya Kebutuhan Kerja Anggota Yang Sekretariat Dan } \\
\text { Anggota DPRD } 0,21\end{array}$ & 0,00 & 0,001 \\
\hline & Jumlah SKOR & 0,45 & 1,23 \\
\hline
\end{tabular}

Sumber Data: Data Primer, 2019

Tabel 2.

Matriks IFE (Kelemahan) Sekretariat DPRD Kabupaten Soppeng

\begin{tabular}{|c|c|c|c|c|}
\hline \multirow[b]{2}{*}{ No } & \multirow[b]{2}{*}{ Faktor-Faktor Kelemahan } & \multicolumn{2}{|c|}{ Total } & \multirow{2}{*}{$\begin{array}{l}\text { Skore } \\
\text { Rating x } \\
\text { Bobot }\end{array}$} \\
\hline & & $\begin{array}{l}\text { Ratin } \\
\mathrm{g}\end{array}$ & Bobot & \\
\hline 1 & $\begin{array}{l}\text { Keterbatasan sarana dan prasarana yang belum lengkap } \\
\text { dan memadai untuk mendukung perkembangan tugas } \\
\text { secretariat DPRD }\end{array}$ & 2,64 & 0,06 & 0,167 \\
\hline 2 & $\begin{array}{l}\text { Akses jaringan internet yang mesih belum memadai di } \\
\text { kantor DPRD Kabupaten Soppeng }\end{array}$ & 3,00 & 0,06 & 0,192 \\
\hline 3 & $\begin{array}{l}\text { Belum optimalnya pemanfaatan sarana teknologi informasi } \\
\text { dalam membantu kinerja layanan sekretariat DPRD } \\
\text { terhadap kebutuhan informasi anggota DPRD (contoh: } \\
\text { Ketersediaan TV berbasis aplikasi dalam menyiapkan } \\
\text { informasi jadwal rapat-rapat anggota DPRD) }\end{array}$ & 3,00 & 0,07 & 0,201 \\
\hline 4 & $\begin{array}{l}\text { Keterbatasan kapasitas sumberdaya manusia yang } \\
\text { professional yang memahami tugas dan fungsinya }\end{array}$ & 3,00 & 0,07 & 0,208 \\
\hline 5 & $\begin{array}{l}\text { Belum tersedianya buku regulasi sebagai salah satu bentuk } \\
\text { pelayanan dalam rangka mendukung kelancaran tugas-tugas } \\
\text { anggota DPRD (Contoh: Buku saku UU, PP, Perpres, } \\
\text { Permendagri) }\end{array}$ & 3,00 & 0,07 & 0,204 \\
\hline 6 & Sistem dan prosedur pelayanan belum optimal & 3,00 & 0,07 & 0,199 \\
\hline 7 & $\begin{array}{l}\text { Kurangnya pemahaman anggota terhadap peraturan } \\
\text { perundang-undangan }\end{array}$ & 3,29 & 0,07 & 0,224 \\
\hline 8 & $\begin{array}{l}\text { Kurangnya pelatihan dan pendidikan yang mampu } \\
\text { meningkatkan kebutuhan kualitas sumber daya Manusia }\end{array}$ & 2,79 & 0,06 & 0,160 \\
\hline 9 & Tidak Adanya Diklat Kepemimpinan Anggota DPRD & 0,29 & 0,01 & 0,002 \\
\hline 10 & $\begin{array}{l}\text { Kurangnya Pemahaman Anggota DPRD Terkait Tata Cara } \\
\text { Pelaksanaan Rapat }\end{array}$ & 0,29 & 0,01 & 0,002 \\
\hline 11 & $\begin{array}{l}\text { Alokasi Anggaran Tidak Merata Sesuai Kebutuhan dan Belum } \\
\text { Berbasis ASB }\end{array}$ & 0,21 & 0,00 & 0,001 \\
\hline 12 & $\begin{array}{l}\text { Aparatur Sekretariat DPRD Masih Mengedepankan Ego } \\
\text { Pribadi }\end{array}$ & 0,21 & 0,00 & 0,001 \\
\hline 13 & Kurangnya Koordinasi Antara STAF & 0,00 & 0,00 & 0,000 \\
\hline 14 & Kurangnya Pegawai PNS & 0,00 & 0,01 & 0,000 \\
\hline & & & 0,55 & 1,557 \\
\hline & Total $(S+W)$ & & 1 & \\
\hline
\end{tabular}


2) Eksternal Factor Evaluation (IFE) pada Sekretariat DPRD Kabupaten Soppeng

Faktor Evaluasi Eksternal (EFE) matriks adalah alat manajemen strategis untuk audit atau mengevaluasi faktor-faktor peluang dan ancaman/hambatan utama terhadap permasalahan peningkatan kinerja layanan Sekretariat DPRD Kabupaten Soppeng. Pada Faktor Evaluasi Eksternal (EFE) juga terdapat dua matriks yakni matriks peluang dan matriks ancaman/hambatan. Matriks tersebut merupakan hasil pengklasifikasian dan pra-analisis peluang dan ancaman/hambatan terhadap kinerja layanan Sekretariat DPRD Kabupaten Soppeng. Faktor-faktor kunci pada faktor peluang dan ancaman/hambatan diberikan penilaian skala rating dan nilai bobot yang kemudian dilakukan kalkulasi bobot dan skala untuk mendapatkan nilai scoring disetiap faktor-faktor kunci. Sebagaimana yang terlihat pada Tabel 3 dan 4 berikut ini.

Tabel 3. Matriks EFE (Peluang) Sekretariat DPRD Kabupaten Soppeng

\begin{tabular}{|c|c|c|c|c|}
\hline \multirow[b]{2}{*}{ No } & \multirow[b]{2}{*}{ Faktor-Faktor Peluang } & \multicolumn{2}{|c|}{ Total } & \multirow{2}{*}{$\begin{array}{l}\text { Skore } \\
\text { Rating } \\
\text { x Bobot }\end{array}$} \\
\hline & & $\begin{array}{c}\text { Ratin } \\
\text { g }\end{array}$ & Bobot & \\
\hline 1 & $\begin{array}{l}\text { Undang-Undang Nomor } 23 \text { Tahun } 2014 \text { tentang Pemerintahan } \\
\text { Daerah mengatur Eksistensi kedudukan Sekretariat DPRD } \\
\text { semakin baik dan strategis }\end{array}$ & 3,21 & 0,09 & 0,277 \\
\hline 2 & $\begin{array}{l}\text { Peraturan Pemerintah Nomor } 18 \text { Tahun } 2016 \text { tentang } \\
\text { Organisasi Perangkat Daerah yang telah mengatur tugas dan } \\
\text { fungsi sekretariat DPRD }\end{array}$ & 3,21 & 0,09 & 0,280 \\
\hline 3 & $\begin{array}{l}\text { Peraturan Bupati Nomor } 43 \text { Tahun } 2016 \text { tentang Kedudukan, } \\
\text { Susunan Organisasi, Tugas dan Fungsiserta Tata Kerja } \\
\text { Sekretariat DPRD Kabupaten Soppeng }\end{array}$ & 3,07 & 0,09 & 0,267 \\
\hline 4 & $\begin{array}{l}\text { Tersedianya Tata Tertib DPRD berdasarkan Peraturan DPRD } \\
\text { yang mendukung pelaksanaan tugas dan fungsi Sekretariat } \\
\text { DPRD }\end{array}$ & 3,43 & 0,09 & 0,304 \\
\hline 5 & $\begin{array}{l}\text { Hubungan kerja yang harmonis antar lembaga DPRD dengan } \\
\text { pemerintah daerah dan Anggota Forkopimda }\end{array}$ & 3,57 & 0,09 & 0,322 \\
\hline 6 & $\begin{array}{l}\text { Adanya kesadaran masyarakat terhadap pentingnya } \\
\text { penyaluran aspirasi secara demokratis ke DPRD }\end{array}$ & 3,07 & 0,09 & 0,275 \\
\hline 7 & $\begin{array}{l}\text { Tersedianya SOP Pelaksanaan Kegiatan Sekretariat Dan Kegiatan } \\
\text { Anggota DPRD }\end{array}$ & 0,21 & 0,01 & 0,001 \\
\hline
\end{tabular}




\begin{tabular}{|c|l|c|c|c|}
\hline 8 & Peningkatan SDM & 0,29 & 0,01 & 0,002 \\
\hline 9 & Memahami Regulasi Yang Berlaku & 0,29 & 0,01 & 0,002 \\
\hline 10 & $\begin{array}{l}\text { Terbukanya Peluang Pengalokasian Anggaran Untuk Pelaksanaan } \\
\text { Fungsi DPRD Melalui Jalur Pokok Pikiran DPRD }\end{array}$ & 0,21 & 0,001 \\
\hline 11 & $\begin{array}{l}\text { Harus Rajin Mengikuti Perkembangan } \\
12\end{array}$ & $\begin{array}{l}\text { Sekretariat Yang Perlu Mengetahui PendalamanTugas } \\
\text { (Bimtek) } 0,21\end{array}$ & 0,01 & 0,001 \\
\hline & 0,001 \\
\hline
\end{tabular}

Sumber Data: Data Primer, 2019

Tabel 4.

Matriks EFE (Ancaman) Sekretariat DPRD Kabupaten Soppeng

\begin{tabular}{|c|c|c|c|c|}
\hline \multirow[t]{2}{*}{ No } & \multirow[b]{2}{*}{ Faktor-faktor ancaman } & \multicolumn{2}{|c|}{ Total } & \multirow{2}{*}{$\begin{array}{l}\text { Skore } \\
\text { Rating x } \\
\text { Bobot }\end{array}$} \\
\hline & & $\begin{array}{c}\text { Ratin } \\
\mathrm{g}\end{array}$ & $\begin{array}{c}\text { Bobo } \\
t\end{array}$ & \\
\hline 1 & $\begin{array}{l}\text { Tuntutan pelaksanaan tugas yang cepat, dan memuaskan dari } \\
\text { anggota DPRD Kabupaten Soppeng sesuai kebutuhan tugas } \\
\text { DPRD }\end{array}$ & 3,21 & 0,08 & 0,262 \\
\hline 2 & $\begin{array}{l}\text { Perubahan peraturan perundang-undangan, pedoman atau } \\
\text { petunjuk teknis secara langsung maupun tidak terkait system } \\
\text { pelayanan dan fasilitas kedewanan yang tidak berbanding lurus } \\
\text { dengan sosialisasi terhadap anggota DPRD dan aparatur } \\
\text { sekretariat DPRD }\end{array}$ & 2,86 & 0,09 & 0,244 \\
\hline 3 & $\begin{array}{l}\text { Adanya perubahan personil melalui mutasi baikpejabat } \\
\text { struktural maupun pejabat fungsional umum }\end{array}$ & 2,50 & 0,07 & 0,181 \\
\hline 4 & $\begin{array}{l}\text { Cepatnya perubahan instrumen penyelenggara pemerintahan } \\
\text { daerah dengan sering berubah- ubahnya peraturan-peraturan } \\
\text { dari pemerintah pusat }\end{array}$ & 2,71 & 0,08 & 0,215 \\
\hline 5 & $\begin{array}{l}\text { Tingginya kesadaran masyarakat terhadap pentingnya } \\
\text { penyaluran aspirasi secara demokratis }\end{array}$ & 2,79 & 0,09 & 0,247 \\
\hline 6 & $\begin{array}{l}\text { Kuragnya Pemahaman Masyarakat Terhadap Prosedur } \\
\text { Penyerapan Aspirasi dan Tata Kerja Pada Saat Penyerapan } \\
\text { Aspirasi }\end{array}$ & 0,29 & 0,01 & 0,002 \\
\hline 7 & $\begin{array}{l}\text { Setiap Anggota DPRD Wajib Memahami Regulasi Yang } \\
\text { Berlaku }\end{array}$ & 0,29 & 0,01 & 0,002 \\
\hline 8 & Peningkatan SDM Anggota dan kesektariatan & 0,29 & 0,01 & 0,002 \\
\hline 9 & $\begin{array}{l}\text { Penyaluran aspirasi masyarakat tidak diimbangi dengan } \\
\text { kompetensi DPRD }\end{array}$ & 0,21 & 0,00 & 0,001 \\
\hline & & & 0,43 & 1,16 \\
\hline & Total $(\mathrm{O}+\mathrm{T})$ & & 1 & \\
\hline
\end{tabular}

Sumber Data: Data Primer, 2019 


\section{Nilai Scoring Tertinggi pada Faktor Kunci Internal dan Eksternal Sekretariat DPRD Kabupaten Soppeng}

Berdasarkan matriks IFE dan EFE yang menyediakan hasil pengidentifikasian dan evaluasi hubungan antara permasalahan terhadap kinerja layanan Sekretariat DPRD Kabupaten Soppeng yang selanjutnya akan digunakan dalam perumusan strategi dalam matriks SWOT. Berikut grafik nilai scoring masing-masing pada factor kekuatan, kelemahan, Peluang dan ancaman/hambatan.

\section{Grafik 1.}

Nilai Scoring Berdasarkan Faktor-Faktor Kekuatan Dimiliki Sekretariat DPRD
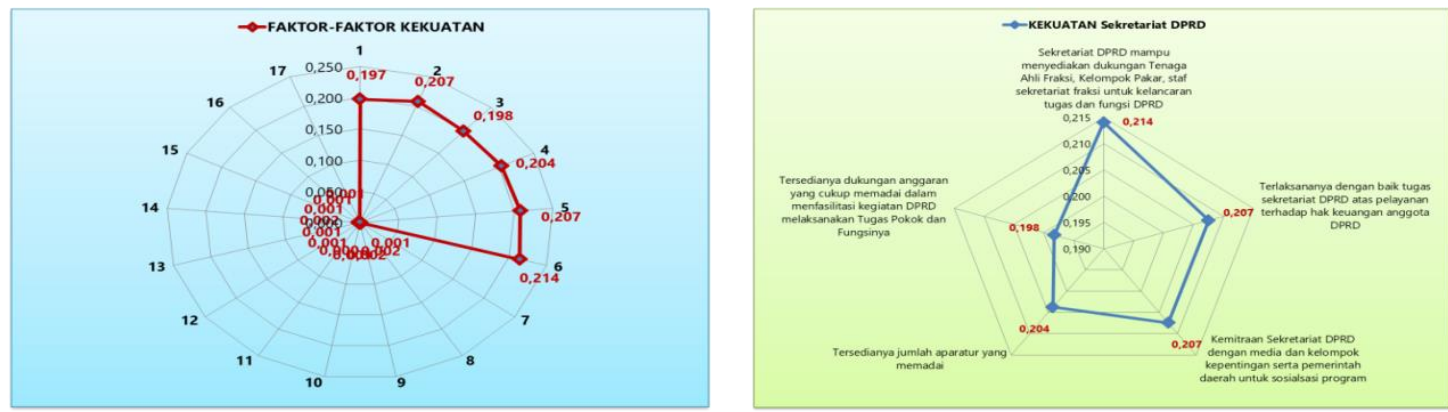

Sumber Data: Data Primer, 2019

Berdasarkan pada Grafik 1 nilai skoring pada faktor kekuatan, kemudian terpilih 5 nilai scoring tertinggi yang kemudian akan digunakan dalam perumusan strategi dalam matriks SWOT untuk peningkatan kinerja layanan Sekretariat DPRD Kabupaten Soppeng, yaitu; 1) Sekretariat DPRD mampu menyediakan dukungan Tenaga Ahli Fraksi, Kelompok Pakar, staf sekretariat fraksi untuk kelancaran tugas dan fungsi DPRD; 2) Terlaksananya dengan baik tugas sekretariat DPRD atas pelayanan terhadap hak keuangan anggota DPRD; 3) Kemitraan Sekretariat DPRD dengan media dan kelompok kepentingan serta pemerintah daerah untuk sosialsasi program; 4) Tersedianya jumlah aparatur yang memadai; dan 5) Tersedianya dukungan anggaran yang cukup memadai dalam menfasilitasi kegiatan DPRD melaksanakan tugas pokok dan fungsinya. 


\section{Grafik 2.}

Nilai Scoring Berdasarkan Faktor-Faktor Kelemahan Dimiliki Sekretariat DPRD
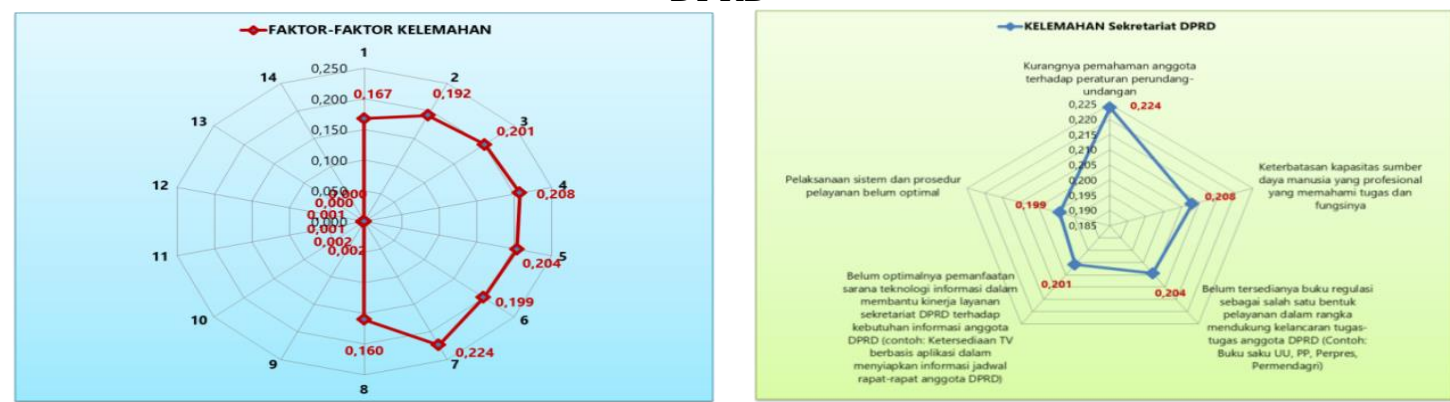

Sumber Data: Data Primer, 2019

Berdasarkan pada Grafik 2 nilai skoring pada faktor kelemahan, kemudian terpilih 5 nilai scoring tertinggi yang kemudian akan digunakan dalam perumusan strategi dalam matriks SWOT untuk peningkatan kinerja layanan Sekretariat DPRD Kabupaten Soppeng, yaitu; 1) Kurangnya pemahaman anggota terhadap peraturan perundang- undangan; 2) Keterbatasan kapasitas sumber daya manusia yang profesional yang memahami tugas dan fungsinya; 3) Belumter sedianya buku regulasi sebagai salah satu bentuk pelayanan dalam rangka mendukung kelancaran tugas-tugas anggota DPRD (Contoh: Buku saku UU,PP, Perpres, Permendagri); 4) Belum optimalnya pemanfaatan sarana teknologi informasi dalam membantu kinerja layanan sekretariat DPRD terhadap kebutuhan informasi anggota DPRD (contoh: Ketersediaan TV berbasis aplikasi dalam menyiapkan informasi jadwal rapat-rapat anggota DPRD); dan 5) Sistem dan prosedur pelayanan belum optimal.

Grafik 3.

Nilai Scoring Berdasarkan Faktor-Faktor Peluang Dimiliki Sekretariat DPRD
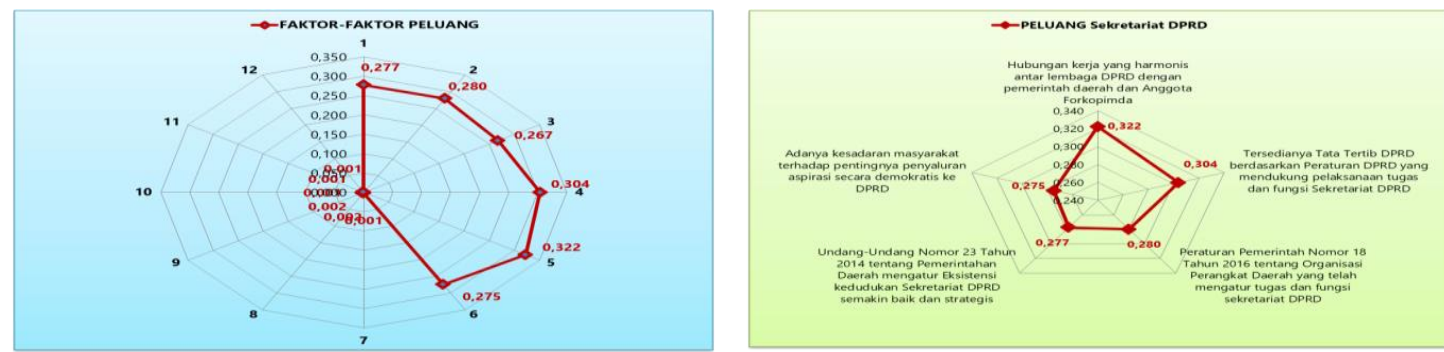

Sumber Data: Data Primer, 2019 
Berdasarkan pada Grafik 3 nilai skoring pada faktor peluang, kemudian terpilih 5 nilai scoring tertinggi yang kemudian akan digunakan dalam perumusan strategi dalam matriks SWOT untuk peningkatan kinerja layanan Sekretariat DPRD Kabupaten Soppeng, yaitu; 1) Hubungan kerja yang harmonis antar lembaga DPRD dengan pemerintah daerah dan Anggota Forkopimda; 2) Tersedianya Tata Tertib DPRD berdasarkan Peraturan DPRD yang mendukung pelaksanaan tugas dan fungsi Sekretariat DPRD; 3) Peraturan Pemerintah Nomor 18 Tahun 2016 tentang Organisasi Perangkat Daerah yang telah mengatur tugas dan fungsi sekretariat DPRD; 4) Undang-Undang Nomor 23 Tahun 2014 tentang Pemerintahan Daerah mengatur Eksistensi kedudukan Sekretariat DPRD semakin baik dan strategis; dan 5) Adanya kesadaran masyarakat terhadap pentingnya penyaluran aspirasi secara demokratis ke DPRD.

\section{Grafik 4.}

Nilai Scoring Berdasarkan Faktor-Faktor Ancaman/Hambatan Dimiliki Sekretariat DPRD
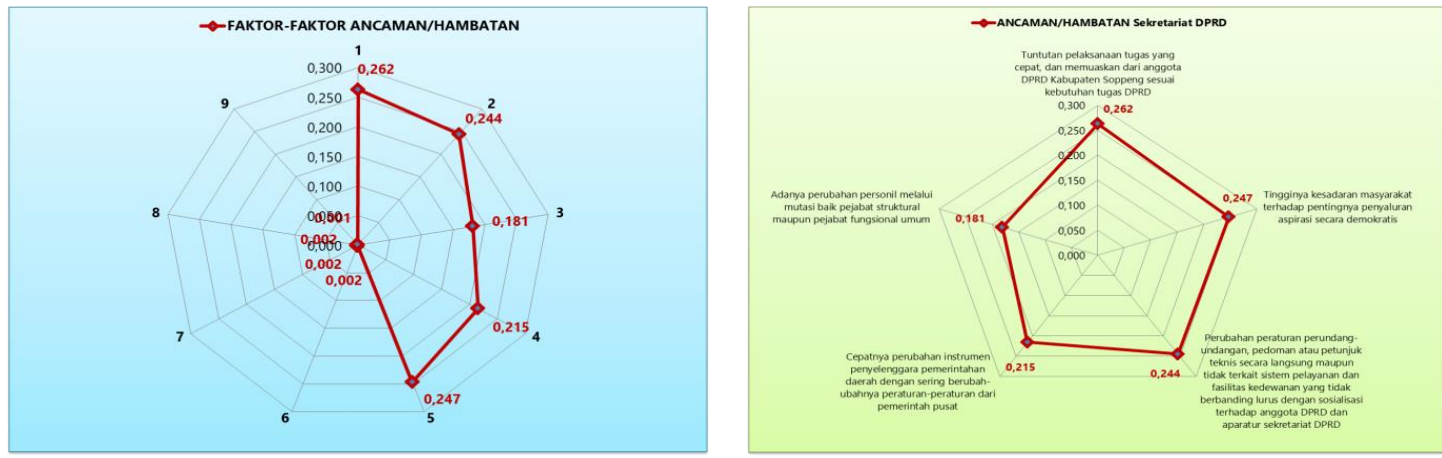

Sumber Data: Data Primer, 2019

Berdasarkan pada Grafik 4 nilai skoring pada faktor acaman/hambatan, kemudian terpilih 5 nilai scoring tertinggi yang kemudian akan digunakan dalam perumusan strategi dalam matriks SWOT untuk peningkatan kinerja layanan Sekretariat DPRD Kabupaten Soppeng, yaitu; 1) Tuntutan pelaksanaan tugas yang cepat, dan memuaskan dari anggota DPRD Kabupaten Soppeng sesuai kebutuhan tugas DPRD; 2) Tingginya kesadaran masyarakat terhadap pentingnya penyaluran aspirasi secara demokratis; 3) Perubahan peraturan perundang-undangan, 
pedoman atau petunjuk teknis secara langsung maupun tidak terkait sistem pelayanan dan fasilitas kedewanan yang tidak berbanding lurus dengan sosialisasi terhadap anggota DPRD dan aparatur sekretariat DPRD; 4) Cepatnya perubahan instrumen penyelenggara pemerintahan daerah dengan sering berubah-ubahnya peraturan- peraturan dari pemerintah pusat; dan 5) Adanya perubahan personil melalui mutasi baik pejabat structural maupun pejabat fungsional umum.

\section{Strategi Peningkatan Kinerja Layanan Sekretariat DPRD Kabupaten Soppeng}

Untuk menyusun strategi peningkatan kinerja layanan Sekretariat DPRD Kabupaten Soppeng dengan meggunakan alanalis SWOT berdasarkan dari faktorfaktor kunci kekuatan (Strengths), kelemahan (Weaknesess) secara internal dan pada faktor-faktor kunci peluang (Opportunity) dan ancaman (Threats) dalam lingkungan yang dihadapi secara eksternal. Kemudian digunakan matriks SWOT sebagai alat pencocokan (matchingtool) dalam menyusun strategi yang efektif untuk memaksimalkan kekuatan dan peluang serta meminimalkan kelemahan dan ancaman (Rangkuti, 2009).

Adapun kekuatan (Strengths), kelemahan (Weaknesess) secara internal dan pada faktor-faktor kunci peluang (Opportunity) dan ancaman (Threats) peningkatan kinerja layanan Sekretariat DPRD Kabupaten Soppeng adalah sebagai berikut :

1) Strenght $(S)$

a) Secretariat DPRD mampu menyediakan dukungan Tenaga Ahli Fraksi, Kelompok Pakar, Staf Sekretariat Fraksi untuk kelancaran tugas dan fungsi DPRD.

b) Terlaksananya dengan baik tugas Sekretariat DPRD atas pelayanan terhadap hak keuangan anggota DPRD.

c) Kemitraan Sekretariat DPRD dengan media dan kelompok kepentingan serta pemerintah daerah untuk sosialisasi program.

d) Tersedianya jumlah aparatur yang memadai. 
e) Tersedianya dukungan anggaran yang cukup memadai dalam menfasilitasi kegiatan DPRD melaksanakan tugas pokok dan fungsinya.

2) Weaknes (W)

a) Kurangnya pemahaman anggota terhadap peraturan perundangundangan.

b) Keterbatasan kapasitas sumber daya manusia yang professional yang memahmi tugas dan fungsinya.

c) Belum tersedianya buku regulasi sebagai salah satu bentuk pelayanan dalam rangka mendukung kelancaran tugas anggota DPRD (contoh : Buku Saku UU, PP, Perpres, Permendagri).

d) Belum optimalnya pemanfaatan sarana teknologi informasi dalam membantu kinerja layanan Sekretariat DPRD terhadap kebutuhan informasi anggota DPRD, pelaksanaan system dan prosedur pelayanan yang belum optimal (contoh : ketersedian TV berbasis aplikasi dalam menyiapkan informasi jadwal rapat-rapat anggota DPRD).

3) Oportunities (0)

a) Hubungan kerja yang harmonis antar lembaga DPRD dengan pemerintah daerah dan anggota Forkopimda.

b) Tersedianya tata tertib DPRD berdasarkan Peraturan DPRD yang mendukung pelaksanaan tugas dan fungus Sekretariat DPRD.

c) Peraturan Pemerintah Nomor 18 Tahun 2016 tentang organisasi Perangkat Daerah yang telah mengatur tugas dan fungsi Sekretariat DPRD.

d) Undang-Undang Nomor 23 Tahun 2014 tentang Pemerintahan Daerah mengatur eksisteni kedudukan Sekretariat DPRD semakin baik dan strategis.

e) Adanya kesadaran masyarakat terhadap pentingnya penyaluran aspirasi secara demokratis ke DPRD.

4) Threats (T) 
a) Tuntutan pelaksanaan tugas yang cepat dan memuaskan dari anggota DPRD Kabupaten Soppeng sesuai kebutuhan DPRD.

b) Tingginya kesadaran masyarakat terhadap pentingnya penyaluran aspirasi secara demokratis.

c) Perubuhan peraturan perundang-undangan, pedoman atau petunjuk teknis secra langsung maupun tidak terkait system pelayanan dan fasilitas kedewanan yang tidak berbanding lurus dengan sosialisasi terhadap anggota DPRD dan aparatur Sekretariat DPRD.

d) Cepatnya perubahan instrument penyelenggara pemerintahan daerah dengan seiring berubah-ubahnya peraturan-peraturan dari pemerinah pusat.

e) Adanya perubahan personil melalui mutasi baik pejabat structural maupun pejabat fungsional umum.

Sedangkan strategi peningkatan kinerja layanan Sekretariat DPRD Kabupaten Soppeng adalah sebagai berikut :

1) Strategi (SO), yakni penyediaan media aspirasi berbasis online dalam mendukung kerja- kerja anggota DPRD dan peningkatan Sosialisasi dan Publikasi terkait tugas, fungsi dan kinerja anggota DPRD.

2) Strategi (W0), yakni peningkatan dukungan pendidikan dan pelatihan pegawai sekretariat dalam menciptakan profesionalitas aparatur sekretariat DPRD dan update informasi dan regulasi melalui Website DPRD yang terintegrasi dengan website pemerintah pusat, provinsi dan kabupaten.

3) Strategi (ST), yakni peningkatan kemampuan adaptasi pegawai secretariat DPRD dalam menyesuaikan perubahan regulasi tanpa mengurangi kualitas layanan.

4) Strategi (WT), yakni penyediaan TV informasi kegiatan anggota DPRD yang berbasis IT dan pembuatan buku saku regulasi dalam mendukung kinerja anggota DPRD. 


\section{KESIMPULAN}

Upaya peningkatan kinerja layanan Sekretariat DPRD Kabupaten Soppeng telah mendapatkan penilaian baik oleh anggota DPRD meskipun masih tetap perlu untuk terus dilakukan peningkatan layanan agar bisa mencapai penilaian sangat baik. Oleh karena itu, untuk meningkatkan kinerja layanan Sekretariat DPRD maka strategi yang dapat dilakukan adalah penyediaan media aspirasi berbasis online dalam mendukung kerja- kerja anggota DPRD dan peningkatan sosialisasi dan publikasi terkait tugas, fungsi dan kinerja anggota DPRD; peningkatan dukungan pendidikan dan pelatihan pegawai sekretariat dalam menciptakan profesionalitas aparatur sekretariat DPRD dan update informasi dan regulasi melalui Website DPRD yang terintegrasi dengan website pemerintah pusat, provinsi dan kabupaten; peningkatan kemampuan adaptasi pegawai secretariat DPRD dalam menyesuaikan perubahan regulasi tanpa mengurangi kualitas layanan; penyediaan TV informasi kegiatan anggota DPRD yang berbasis IT dan pembuatan buku saku regulasi dalam mendukung kinerja anggota DPRD. maka dari itu, disarankan kepada Sekretaris DPRD Kabupaten Soppeng melakukan pengukuran indeks layanan agar dapat melihat kelebihan dan kekurangan disetiap bidang yang ada di Sekertariat DPRD, selain itu dapat menjadi evaluasi kinerja layanan Sekretariat DPRD secara berkala.

\section{REFERENSI}

Annas, A., \& Anirwan, A. (2019). Upaya Peningkatan Kinerja DPRD Kabupaten Soppeng.Journal of Governance and Local Politics, 1(2), 82-99.

Dwiyanto, A. 2006. Penilaian Kinerja Organisasi Publik, Makalah Dalam Seminar Sehari: Kinerja Organisasi Sektor Publik, Kebijakan dan Penerapannya. Fisipol UGM, Yogyakarta.

Harahap, A. S., \& Angelia, N. (2016). Peranan Promosi Jabatan Terhadap Kinerja Pegawai Negeri Sipil Di Sekretariat DPRD Kabupaten 
Padang Lawas. Publikauma: Jurnal Administrasi Publik Universitas Medan Area, 4(1), 29-42.

Mukhlishoh, I., Hamid, A., \& Arenawati, A. (2016). Pengaruh motivasi kerja terhadap kinerja pegawai di sekretariat Dewan Perwakilan Rakyat Daerah (DPRD) Provinsi Banten (Doctoral dissertation, Universitas Sultan Ageng Tirtayasa).

Novitasari, A. (2014). Evaluasi terhadap implementasi standar pengukuran kinerja karyawan bagian umum untuk meningkatkan kualitas layanan keluhan masyarakat di Kantor DPRD Propinsi Jawa Timur. CALYPTRA, 3(1), 1-9.

Septiani, E. (2018). Analisis Kinerja Pegawai Dalam Penyelengaraan Pelayanan Publik Di Sekretariat DPRD Kota Sungai Penuh. Jurnal Administrasi Nusantara, 1(2), 58-73.

Sutanti, N. (2014). Strategi Peningkatan Kualitas Layanan Di Sekretariat DPRD Kabupaten Magelang Tahun 2012. Jurnal Riset Manajemen Sekolah Tinggi Ilmu Ekonomi Widya Wiwaha Program Magister Manajemen, 1(1), 1-21

Rangkuti F D. 2005. Strategic Management Concepts and Cases Ninth Edition. New Jersey, Prentice Hall.

Ratminto, dan Winarsih. 2013. Manajemen Pelayanan. Pustaka Pelajar, Yogyakarta.

Zamzam, F. (2016). Pengaruh Pengembangan Karier dan Iklim Organisasi terhadap Kinerja Pegawai Sekretariat DPRD Kabupaten OKI dengan Variabel Kepuasan Kerja sebagai Intervening. Ekonomica Sharia, 1(2), 1-12.

\section{Dokumen-Dokumen}

Peraturan Bupati Kabupaten Soppeng Nomor 43 Tahun 2016 tentang Kedudukan, Susunan Organisasi, Tugas dan Fungsi serta Tata 
Kerja Sekretariat DPRD Kabupaten Soppeng. Sekretariat DPRD Soppeng.

Peraturan Bupati Kabupaten Soppeng Nomor 32 Tahun 2019. Kedudukan, Susunan Organisasi, Tugas dan Fungsi serta Tata Kerja Sekretariat DPRD Kabupaten Soppeng.

Peraturan Daerah Nomor 5, Tahun 2016 tentang Pembentukan dan Susunan Perangkat Daerah Kabupaten Soppeng.

Peraturan DPRD Kabupaten Soppeng Nomor 1 Tahun 2018 tentang Tata Tertib Sekretariat DPRD Soppeng.

Peraturan Pemerintah Nomor 18 Tahun 2016 tentang Perangkat Daerah.

Peraturan Pemerintah Nomor 12 Tahun 2018 Tentang Pedoman Penyusunan Tata Tertib DPRD Provinsi, Kabupaten, dan Kota.

Sekretariat DPRD. 2016. Laporan Kinerja Sekretariat DPRD Kabupaten Soppeng.

Sekretariat DPRD. 2017. Laporan Kinerja Sekretariat DPRD Kabupaten Soppeng.

Sekretariat DPRD. 2018. Laporan Kinerja Sekretariat DPRD Kabupaten Soppeng.

Sekretariat DPRD. 2019. Laporan Kinerja Sekretariat DPRD Kabupaten Soppeng.

Undang-Undang Nomor 23 Tahun 2014 tentang Pemerintahan Daerah. 